\title{
Vojta method in the treatment of developmental hip dysplasia - a case report
}

This article was published in the following Dove Press journal:

Therapeutics and Clinical Risk Management

19 August 2016

Number of times this article has been viewed

\section{Wojciech Kiebzak ${ }^{1,2}$ \\ Arkadiusz Żurawski \\ Michał Dwornik ${ }^{3}$ \\ 'Center for Pediatrics, Regional Hospital in Kielce, Kielce, Poland; ${ }^{2}$ Department of Physiotherapy, Faculty of Medicine and Health Sciences, Jan Kochanowski University, Kielce, Poland; ${ }^{3}$ Department of Osteopathic Medicine and Physiotherapy, Medical College of Podkowa Lesna, Podkowa Lesna, Poland}

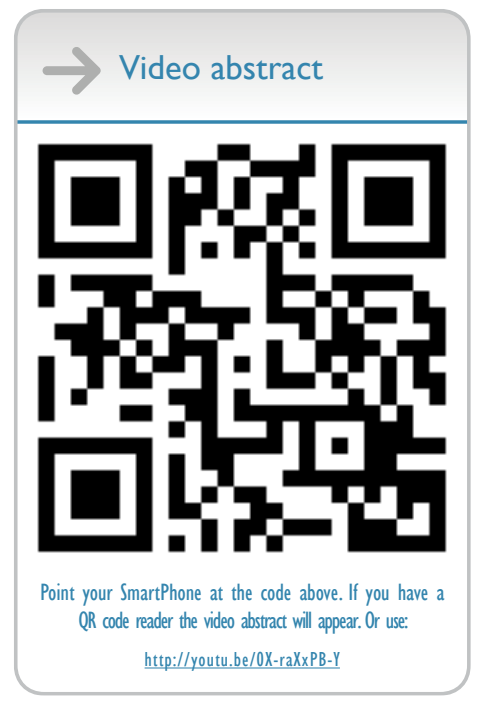

Correspondence: Michał Dwornik Department of Osteopathic Medicine and Physiotherapy, Medical College of Podkowa Lesna, Modrzewiowa 45, 05-807 Podkowa Lesna, Poland

Tel +48505045790

Emaildmdwornik@wp.pl
Background: Developmental dysplasia of the hip joint is one of the most common congenital defects and often results in functional and structural disorders. Such cases particularly demand optimizing therapeutic effects and maximally reducing the duration of therapy.

Purpose: The aim of this case report is to present the therapeutic process in a child with developmental hip dysplasia.

Case report: This is a case report of a female child with a birth weight of 2,800 $\mathrm{g}$ and an Apgar score of 9 points born to a gravida 3 para 3 mother at 37 weeks. The child was delivered by cesarean section, and the pregnancy was complicated by oligohydramnios. Subluxation of the left hip joint was diagnosed by an orthopedist in the third month of life. The treatment followed was the Vojta method (the first phase of reflex turning and reflex crawling).

Results: During the 6 weeks of the Vojta treatment, the left half of the femoral head was centralized, and the process of formation of the hip joint acetabulum was influenced effectively enough to change the acetabulum's Graff type from the baseline D to IIb after 41 days of treatment.

Conclusion: The diagnostic work-up of congenital hip joint dysplasia should involve a physiotherapist who will investigate the child's neuromuscular coordination, in addition to a neonatologist and a pediatrician. The therapy for a disorder of hip joint development of neuromotor origin should involve the application of global patterns according to Vojta. Children with congenital dysplasia of the hip joint should commence rehabilitation as early as possible.

Keywords: global pattern, neuromuscular coordination, centralization of the the femoral head

\section{Introduction}

Congenital dysplasia of the hip joint is one of the most common congenital defects in Caucasians. Approximately $4 \%$ of neonates demonstrate unequivocal signs of dysplasia, and $1.5 \%$ present with an evident dislocation of the femoral head. Hip joint dysplasia affects girls much more often than boys, with a female-to-male ratio of 4:1. The left hip joint is affected twice as often as the right. ${ }^{1}$

A number of theories have been proposed to explain the cause of dislocation of the femoral head in the hip joint acetabulum and abnormal development of this part of the bony pelvis. Mostly, attention has been given to fetal positioning in the prenatal period, the effect of hormones on laxity of the articular capsule, and the genetic factor. However, an extensive review of the available literature by Seringe et al points to the positioning of the joint during fetal development as the most significant factor. ${ }^{2-5}$

In most cases of hip joint dysplasia, the femoral head is not dislocated against the acetabulum. This changes when the child makes its initial attempts at standing. The acetabulum, which covers too little of the femoral head, cannot hold the femoral head in its normal position relative to the horizontal vector of gravity. The result is gradual 
displacement of the femoral head, which usually stops for a shorter or longer period at the following characteristic anatomic landmarks:

- Upper rim of the acetabulum - sublocatio

- Just above the acetabulum - luxatio supracotyloidea

- Iliac ala - luxatio iliaca.

Prolonged exposure of these areas to the femur can lead to changes in the bone tissue within both the acetabulum and the femoral head. Secondary acetabula are formed, that is, depressions in the bone, and there may be lengthening and shallowing of the acetabulum with atrophy of the upper rim and exaggeration of the fundal depression, or the acetabular fundus may fill with fatty tissue. Femoral deformities include an increased neck-shaft angle, increased antetorsion, or even flattening of the femoral head at its pelvic contact surface. All those abnormalities are obviously associated with soft tissue problems. ${ }^{6,7}$

Diagnostic work-up in congenital hip joint dysplasia is now turning away from tests known from older orthopedics textbooks, such as the Ortolani test or the Barlow test. ${ }^{8-10}$ The ever advancing modalities of diagnostic imaging (radiography and ultrasound) are used to establish a certain diagnosis and determine the degree of dysfunction. Effective radiographs can only be obtained in children aged $\geq 4$ months, when ongoing mineralization of the hip joint allows visualizing the acetabular roof and the femoral head ossification nucleus. The impossibility of ensuring a fully symmetrical position of the infant patient is an additional impediment to radiographic assessment. A number of auxiliary lines are plotted in the image to increase reliability of conclusions, including Putti's lines, Higienreiner's method, Ombredanne-Perkins lines, Shenton-Menard arch, or Wiberg's angle. The necessity of early diagnosis and the capability of visualizing cartilage and soft tissue structures strongly favor the ultrasound as the dominant tool for reliably diagnosing hip dysplasia. ${ }^{11}$

A screening examination, which may lead to further targeted work-up, can and should be performed already in the neonatal ward. However, it should not be the responsibility of the pediatrician and the neonatologist alone. Abnormalities of joint integrity often pass unnoticed at the initial physical examination, but they may be diagnosed by physiotherapists in a functional palpation examination of the hip joint. Abnormal neuromuscular coordination, especially in the lower limbs, may lead to positioning of the limb in extension, adduction, and internal rotation, or in some cases, in flexion and hyperadduction, which should immediately raise a suspicion of a hip joint abnormality. These characteristic positions are often accompanied by asymmetrical tonic reflexes, torticollis, body axis asymmetry, elevated extension reflexes in the lower limbs (in bilateral hip dysplasia), or even equinovarus foot. The precise identification of the nature and location of the dysfunction benefits from Vojta's neurokinesiologigal diagnostic and therapeutic approach, which involves assessment of primary reflexes and seven provocative positional reactions which influence the sensorimotor function of the pelvic girdle muscles. ${ }^{12}$

The treatment of hip joint dysplasia may be divided into three categories:

- functional therapy,

- orthopedic aids and tractions, and

- surgery.

The management of a particular patient should always be matched to the stage of hip dysplasia and the child's motor and emotional capacities, and the governing principle should be that of striving for a maximum therapeutic effect at a minimal strain of the patient. Secondary manifestations of untreated or undertreated hip joint dysplasia may include musculoskeletal dysfunctions such as postural defects, scolioses, and painful functional and structural abnormalities of the lumbosacral spine. ${ }^{13}$

The idea motivating the use of orthopedic aids, such as diverse types of distractors, cushions, splints, or tractions, is to induce slow passive centering of the femoral head toward the acetabular fundus. While this approach is effective, it does not provide for the development of appropriate functional conditions for the joint in the new biomechanical conditions. Without the support and stabilization afforded by complete muscle chains and without work to develop motor functions, prolonged treatment-related immobilization often produces problems of structural (contractures of muscles, ligaments, and the joint capsule) and functional (impaired support function, development of abnormal extension reactions) nature. ${ }^{7}$ A major biomechanical mechanism that is activated during therapy is the stimulation of proprioceptors which induces efferent stimuli and contribute to the normalization of biomechanical relations in the pelvic girdle. ${ }^{14}$

\section{Purpose}

The aim of this case report is to present the therapeutic process and its effects in a child with developmental hip dysplasia.

\section{Case report}

A child was referred to diagnosis method of Vojta which consists of observing the behavior of the child, and the arrangement of the head, spine, limbs in the hip joints, and the hands and feet. The test shall be carried out on the basis of seven reactions as implemented by Vojta. Evaluation of spontaneous 


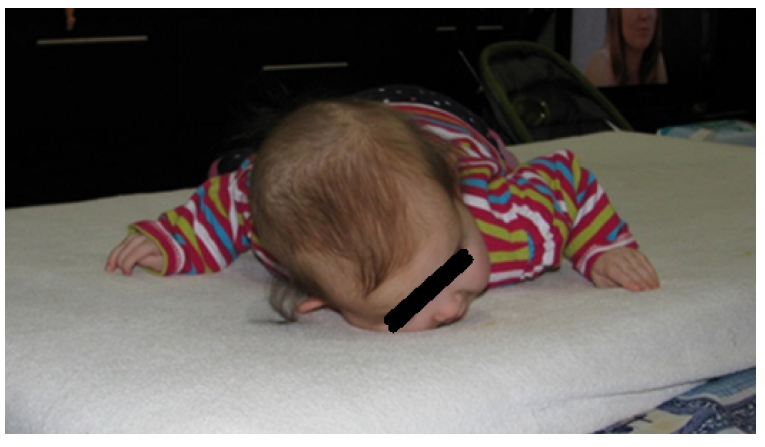

Figure I The child's functional status: there is visible asymmetry and impaired support function.

behaviors in the position on the back and the belly, evaluation of neurological reflexes, and the sum of observations help in the diagnosis of the so-called central coordination disorder with regard to irregularities, for example, in the hip joint. The tests shall be carried out every 3-4 weeks. Children are functionally tested during each visit with respect to reactions according to the arrangement proposed by Vojta and spontaneous motor reactions (Figure 1). Therapy involves provocation, stimulation of global movement patterns, and above all, reflexive body rotation and creep. In provoked patterns are physiological components of the axial spine movement. The therapy is performed several times a day for 3-20 minutes.

This is a case report of a female child born to a gravida 3 para 3 mother on 23 May, 2014, at 37 hbd with a birth weight of 2,800 $\mathrm{g}$ and an Apgar score of 9 points. The child was delivered by cesarean section, and the pregnancy was complicated by oligohydramnios. Subluxation of the left hip joint was diagnosed by an orthopedist in the third month of life (Figures 2 and 3). The child was referred to a physiotherapist shortly before a scheduled imaging examination of the hip joints with evidence of neonatal development. The child presented with impaired support function of the upper limbs, asymmetrical positioning of the head and trunk, and a characteristic tendency toward placing the left lower limb in extension, adduction, and internal rotation.

Functional examination revealed an absent plantar grasp in the right hand, and an incorrect arrangement of the right hand and the lack of proper support with simultaneous elevation of the head (Figure 1). Positive asymmetric tonic neck reflex and exaggerated extension responses in the left lower limb during the testing of the suprapubic reflex and the crossed extensor reflex were observed. An evaluation of the positioning reactions revealed five abnormal positions, with marked elevation of muscle tone on the left. These findings prompted the physiotherapist to refer the child for an orthopedic consultation. This disorder is correlated with dysplasia of the hip.

The therapy relied on global motor patterns based on the Vojta method. Condition of full activity of man depends on smooth rotation around the axis of the body, with particular regard to the passage of cervical-thoracic and thoraciclumbar spine with correct muscle activity of the serratus posterior superior and interior muscles.

Vojta method focuses on the control of the cervicalthoracic and thoracic-lumbar spine transition to achieve a symmetrical position of the shoulder and pelvic girdles, concentric activity of the abdominal muscles, activity of autochthonous muscles, and normal muscle activity within the hip joint. Reflex crawling is used to produce activity within the so-called occipital lower limb, proximal attachments, and positioning (penetration) of the hip acetabulum by the femoral head, which positions itself in external rotation, abduction, and some flexion. Children with developmental disorders of the hip joints (clinically diagnosed with hip joint dysplasia) turn about in an abnormal manner, which is taken account of during the diagnostic work-up, where dysfunctions of one joint affect the motor function of the whole body; accordingly, the authors recommend that patients should be viewed both diagnosis- and therapy-wise.

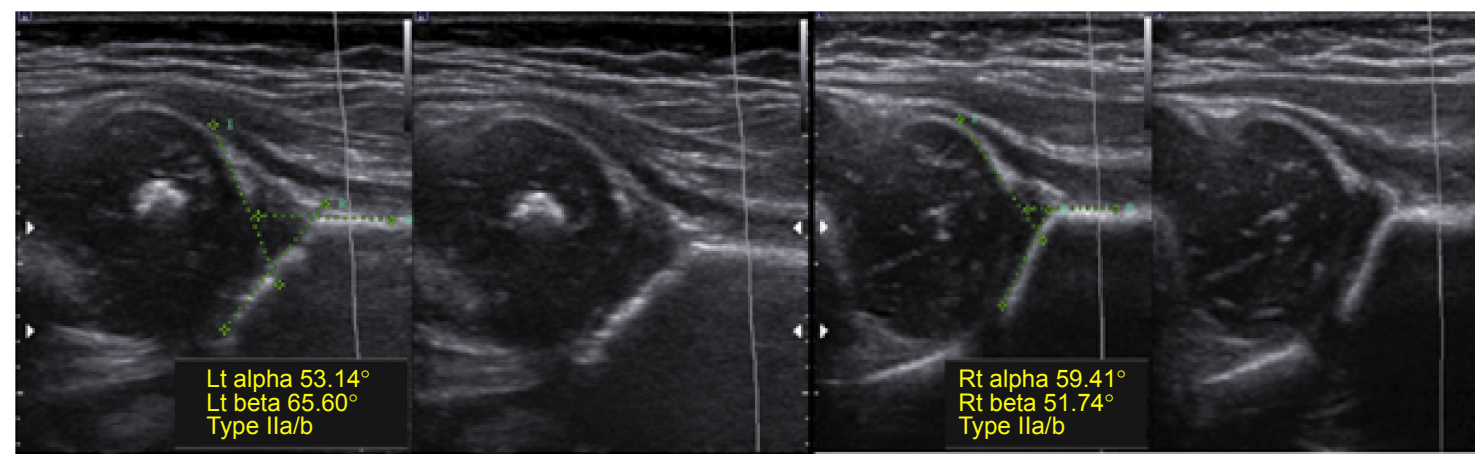

Figure 2 An ultrasound examination of the hip joints: right hip joint - type lla (alpha angle of $59^{\circ}$ ) without decentralization and left hip joint - a dysplastic acetabulum (alpha angle of $53^{\circ}$ ) (August I, 2014).

Note: The correct value of alpha angle is $\geq 60^{\circ}$, and that of beta angle is $>55^{\circ}$

Abbreviations: Lt, left; Rt, right. 


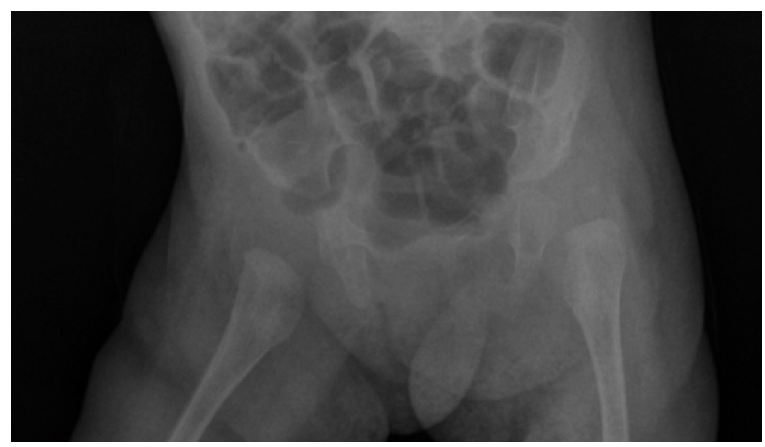

Figure 3 X-ray of dysplastic hip joints (August 2, 20I4).

\section{Results}

During the 6 weeks of the therapy, we were able to achieve centralization of the left half of the femoral head and influence the formation of the hip joint acetabulum effectively enough to change the acetabulum's Graff type from the baseline D (dysplastic type of Graff classification - type IIIa/IIIb, type IV) (Figures 2 and 3) to IIb (type of Graff classification) (Figures 4 and 5) after 41 days of treatment.

\section{Discussion}

The use of neurophysiological techniques in the diagnosis and rehabilitation of patients with developmental dysplasia of the hip joint is crucial for treatment efficacy. A review of the MEDLINE database revealed no relevant publications. The importance of early functional diagnosis and rehabilitation is appreciated in other childhood diseases, as reflected in the extensive literature available. ${ }^{15}$

With the Vojta method, the duration of treatment of the dysplastic hip can be reduced considerably (Figures 4 and 5). In our patient, who was diagnosed with developmental hip dysplasia at the age of 9 weeks, repositioning was completed within 6 weeks. Duration of treatment is similar corresponding to the age of the child at the beginning of treatment. ${ }^{16}$

In a study by Pap et al on $~ 900$ children with developmental dysplasia of the hip treated with Pavlik's harness, treatment duration was actually longer by a third. Thus, the use of Vojta method in our patient apparently reduced the duration of treatment by $50 \%{ }^{17}$

Complications following treatment, which may result from prolonged immobilization of the hip joints and manifest as limited ranges of motion in the hip joints due to contractures of the hip abductors, external rotators, or iliopsoas muscles, are a very important aspect. ${ }^{7}$

The most serious complication is femoral head necrosis, with an incidence of $9.6 \%$ of those patients treated with Pavlik's harness. ${ }^{13}$ Niethard showed that it is possible to reduce this rate to $4 \%$ if neurophysiological techniques are used during treatment. ${ }^{18}$

Orthopedic aids have an adverse effect on the child's development. With limited movement in the lower body, the baby is deprived of opportunities to stimulate the motor development of the lower limbs, and later, also rotational movements, which interferes with the totality of ideomotor processes. Despite good treatment outcomes, the support functions of the lower limbs should be carefully monitored using objective measuring tools during the child's later development to identify any persistent ideomotor abnormalities. ${ }^{19}$ In later development, children with a history of developmental dysplasia of the hip should also be carefully monitored with regard to the biomechanical functions of the spinal column. ${ }^{20}$ In this regard, the advantages of using neurophysiological techniques during treatment appear obvious. Even in very advanced hip dysplasia, when surgery is necessary on account of the extent of the abnormality, it is advised that the patient regularly attend neurodevelopmental therapy sessions to limit the adverse consequences of the core treatment. ${ }^{9}$

Considerable therapeutic benefit in the early treatment of hip joint dysplasia is the sensorimotor therapy of central coordination according to Vojta. ${ }^{21}$ The motor therapy takes advantage of normal muscular interplay, particularly that between the hip joint adductors and external rotators, whose activity maintains both components of the joint in

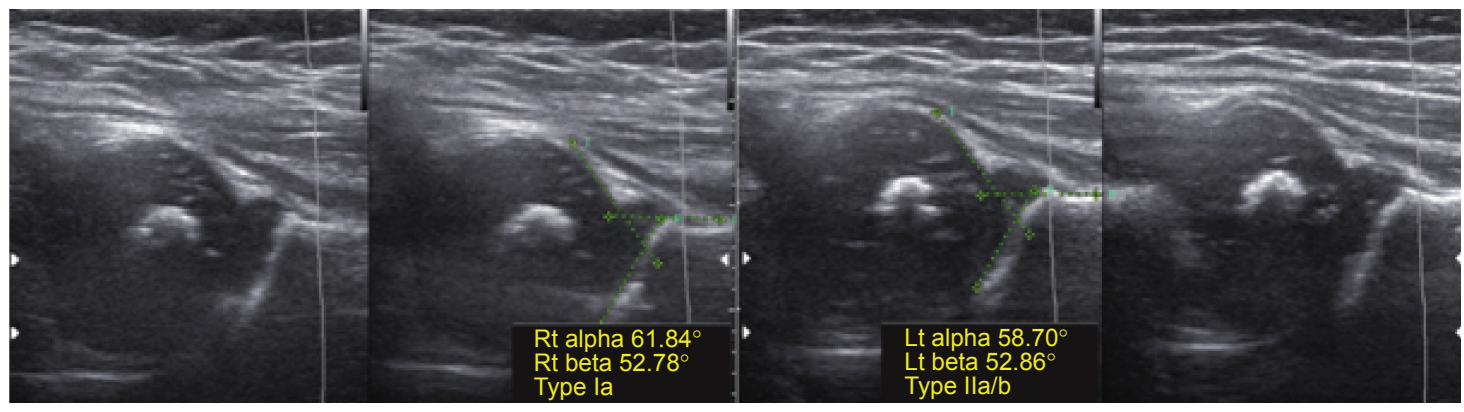

Figure 4 Ultrasounds of the hip joints: right hip joint - type la (alpha angle is $\geq 60^{\circ}$ ) and left hip joint - type llb (alpha angle of $58^{\circ}$ ) without decentralization $(O c t o b e r ~ 2,20 I 4)$. Abbreviations: Lt, left; Rt, right. 


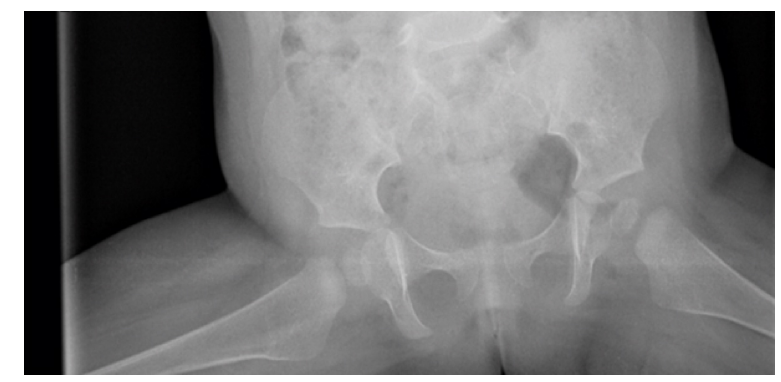

Figure 5 X-ray of hip joints (October 12, 2014).

their normal anatomical relation, while the activity of these muscles provides for centering the acetabulum relative to the femoral head. Only a physiological distribution of pressure and stretch forces under the Delpech-Wolff law can ensure normal formation of the developing acetabulum. Neurophysiological methods approach the patient holistically; besides exerting a beneficial influence on articular structures, they also allow for the development of normal muscular interplay, thus stimulating overall motor development of the child. While such approaches do have their limits related to the severity of the dysplasia or the rate of formation of bony structures, they are useful even in very advanced cases, helping to condition the articular capsule muscles before surgery. ${ }^{22}$

\section{Conclusion}

The diagnostic work-up of congenital hip joint dysplasia should involve, apart from a neonatologist and a pediatrician, a physiotherapist, who will investigate the child's neuromuscular coordination. The therapy of a disorder of hip joint development of neuromotor origin should involve the application of global patterns according to Vojta. Children with congenital dysplasia of the hip joint should commence rehabilitation as early as possible.

\section{Acknowledgments}

This research was supported by funding from the Centre for Paediatrics of the Regional Hospital in Kielce. The patient's parents provided written informed consent agreeing to the publication of the data and images in this report.

\section{Disclosure}

The authors report no conflicts of interest in this work.

\section{References}

1. Liu Q, Wang Y, Liu Y. [Early screening of developmental dysplasia of the hip among hospitalized children]. Zhonghua Yi Xue Za Zhi. 2014;94(20):1567-1569. Chinese.

2. Seringe R, Bonnet JC, Katti E. [Pathogeny and natural history of congenital dislocation of the hip]. Rev Chir Orthop Reparatrice Appar Mot. 1990;76(6):391-402. French.
3. Wenger D, Düppe H, Tiderius CJ. Acetabular dysplasia at the age of 1 year in children with neonatal instability of the hip. Acta Orthoped. 2013;84(5):483-488.

4. Sewell MD, Eastwood DM. Screening and treatment in developmental dysplasia of the hip-where do we go from here? Int Orthop. 2011;35(9):1359-1367.

5. Brand RA. Etiology of congenital dislocation of the hip. Clin Orthop Relat Res. 2008;466(1):90-103.

6. Hägglund G, Alriksson-Schmidt A, Lauge-Pedersen H. Prevention of dislocation of the hip in children with cerebral palsy: 20-year results of a population-based prevention programme. Bone Joint J. 2014; 96-B(11):1546-1552.

7. Oberc A, Sułko J, Szydłowski M. Dysplasia epiphysealis hemimelicadiagnostics and treatment in pediatric patients. Pol Orthop Traumatol. 2014;79:41-44.

8. Eastwood DM. Neonatal hip screening. Lancet. 2003;361(9357): 595-597.

9. Paton RW. Screening for hip abnormality in the neonate. Early Hum Dev. 2005;81(10):803-806.

10. Chow YW, Turner I, Kernohan WG, Mollan RA. Measurement of the forces and movements involved in neonatal hip testing. Med Eng Phys. 1994;16(3):181-187.

11. De Pellegrin M, Tessari L. Early ultrasound diagnosis of developmental dysplasia of the hip. Bull Hosp Jt Dis. 1996;54(4):222-225.

12. Sliwiński Z, Kufel W, Michalak B, et al. The assessment of pelvic statics in patients with spinal overload syndrome treated in whole-body cryotherapy. Ortop Traumatol Rehabil. 2005;7(2):218-222.

13. Dwornik M, Białoszewski D, Kiebzak W, Lyp M. The correlation of selected physical examination findings and the efficacy of physiotherapy for chronic lumbosacral pain. Ortop Traumatol Rehabil. 2007; 9(3):297-309.

14. Osugi T, Iwamoto J, Yamazaki M, Takakuwa M. Effect of a combination of whole body vibration exercise and squat training on body balance, muscle power, and walking ability in the elderly. Ther Clin Risk Manag. 2014;10:131-138.

15. Reimunde P, Rodicio C, López N, Alonso A, Devesa P, Devesa J. Effects of recombinant growth hormone replacement and physical rehabilitation in recovery of gross motor function in children with cerebral palsy. Ther Clin Risk Manag. 2010;6:585-592.

16. Niethard FU. Krankengymnastische Behandlung auf neurophisiologoscher Grundlage bei orthopadischen Erkrankungen im Kindesalter (Teil 1) [Physiotherapy treatment on neurophysiologic basis for orthopedic diseases in childhood (Part 1)]. Sosialpadiatrie. 1987;9:512. German.

17. Pap K, Kiss S, Tshiha T, Marton-Szücs G, Szöke G. The incidence of avascular necrosis of the healthy, contralateral femoral head at the end of the use of Pavlik harness in unilateral hip dysplasia. Int Orthop. 2006;30(5):348-351.

18. Niethard FU. Die Vorbehandlung der kongenitalen Hüftgelenksluxation mit krankengymnastischer Therapie auf neurophysiologischer Basis [Preliminary treatment of congenital hip dislocation using physical therapy based on neurophysiology]. Z Orthop Ihre Grenzgeb. 1987;125(1):28-34. German.

19. Domagalska-Szopa M, Szopa A. Postural pattern recognition in children with unilateral cerebral palsy. Ther Clin Risk Manag. 2014;10: $113-120$.

20. Kowalski IM, Protasiewicz-Fałdowska H, Dwornik M, Pierożyński B, Raistenskis J, Kiebzak W. Objective parallel-forms reliability assessment of 3 dimension real time body posture screening tests. $B M C$ Pediatr. 2014;14:221.

21. Kiebzak W, Kowalski IM, Domagalska M, et al. Assessment of visual perception in adolescents with a history of central coordination disorder in early life - 15-year follow-up study. Arch Med Sci. 2012;8(5): 879-885.

22. Barczyk K, Wojtowicz D, Hawrylak A, Mraz M. Zaburzenia ośrodkowej koordynacjinerwowej (zokn) a ruchomość stawów biodrowych u niemowląt [Disorders of central coordination (zokn) and the mobility of the hip in infants]. Prz Pediat. 2009;39(2):110-116. Polish. 


\section{Publish your work in this journal}

Therapeutics and Clinical Risk Management is an international, peerreviewed journal of clinical therapeutics and risk management, focusing on concise rapid reporting of clinical studies in all therapeutic areas, outcomes, safety, and programs for the effective, safe, and sustained use of medicines. This journal is indexed on PubMed Central, CAS,

EMBase, Scopus and the Elsevier Bibliographic databases. The manuscript management system is completely online and includes a very quick and fair peer-review system, which is all easy to use. Visit http://www.dovepress.com/testimonials.php to read real quotes from published authors.

Submit your manuscript here: http://www.dovepress.com/therapeutics-and-clinical-risk-management-journal 